\title{
Dos cartas de Ceán Bermúdez para el origen de la historia de la arquitectura española
}

Two letters from Ceán Bermúdez for the origin of the history of Spanish architecture

Daniel Crespo Delgado

Fundación Juanelo Turriano

CESXVIII, núm. 28 (2018), págs. 419-428 DOI: https://doi.org/10.17811/cesxviii.28.2018.419-428

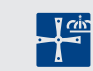




\section{RESUMEN}

Damos a conocer dos cartas inéditas de Ceán Bermúdez, fechadas en 1798, y dirigidas al archivero de la catedral de Sevilla, Antonio de San Martín. Estas cartas nos permiten conocer mejor el proceso de recopilación de noticias sobre arquitectos llevado a cabo por Ceán, que resultó en la primera historia moderna de la arquitectura en España.

Palabras clave

Juan Agustín Ceán Bermúdez, Jovellanos, Catedral de Sevilla.

\section{AbSTRACT}

We transcribe two unpublished letters, dated in 1798, from Ceán Bermúdez to Antonio San Martín, archivist of the cathedral of Seville. These letters allow us a better comprehension of Ceán's research of Spanish architects' notices.

Key Words

Juan Agustín Ceán Bermúdez, Jovellanos, Catedral de Sevilla.

Recibido: 6 de junio de 2018. Aceptado: 22 de junio de 2018. 
Las dos cartas que presentamos fueron remitidas por Juan Agustín Ceán Bermúdez (1749-1829) al archivero de la catedral de Sevilla, Antonio de San Martín ${ }^{1}$. Fueron enviadas desde Madrid en enero y marzo de 1798 respectivamente. En la primera de ellas, el erudito asturiano solicitó al archivero noticias sobre los arquitectos que habían intervenido en la catedral de Sevilla. De la propia carta se deduce que San Martín ya le había proporcionado con anterioridad referencias sobre otros artistas que habían trabajado en dicha catedral; sin embargo, en aquel momento no le interesaron las relativas a los arquitectos. Ahora, su opinión había cambiado y, por sugerencia de Jovellanos, había decidido incluir a los arquitectos en sus pesquisas ${ }^{2}$.

Recordemos que durante su segunda estancia en Sevilla (1791-1797), Ceán empezó a recopilar sistemáticamente noticias sobre artistas que habían desarrollado su obra en España ${ }^{3}$. Continuó con esta tarea tras su traslado a Madrid a finales de 1797, publicando en 1800 un trabajo que desde su aparición se convirtió en una referencia ineludible de la historia del arte: el Diccionario histórico de los más ilustres profesores de las bellas artes en España. Es sabido que, finalmente, en el Diccionario no se incluyeron arquitectos. En el prólogo Ceán explicó que los abarcó en sus investigaciones, pero no se resolvió a sumarlos a su libro al creer que, dada la relevancia de la arquitectura - «sobrepuja a

$1 \quad$ Sevilla, Archivo de la Catedral de Sevilla, sección IX, caja 11.289, doc. 7.

2 Esto concuerda con algunos de los materiales manuscritos del trabajo de Ceán que conservamos de este periodo. En la Copia de la obra de Ceán en lo concerniente a Bellas Artes y sus profesores en Sevilla (Madrid, Archivo de la Real Academia de la Historia, Colección Vargas Ponce, sign. 9/4.176, vol. 3, ff. 279r$302 v$ ), fechable hacia 1794, Ceán toma como punto de partida la descripción de Sevilla del tomo IX (1780) del Viage de España de Antonio Ponz, corrigiendo y añadiendo lo que el secretario de la Academia de San Fernando había errado u olvidado. Sin embargo, no atiende a las noticias relativas a la arquitectura, sino sólo a las de la pintura y la escultura. Anotemos que este recorrido hispalense de Ceán se inicia en la catedral, donde ya corrige a Ponz, por ejemplo sobre la autoría de la sillería del coro: «un erudito canónigo de esta santa iglesia (¿Gil de Araujo?), amigo mío, tiene averiguado que el Alborique que se lee en otra silla de este coro, y que Ponz ha sospechado poder ser nombre de algún alarife, no lo es, sino de un animal simbólico del Alcorán» (f. 284v).

3 David García López ha situado con precisión el inicio del Diccionario en su artículo «Más parece hecha por una sociedad de lavoriosos individuos, que por un solo. El método de trabajo de Ceán Bermúdez», aparecido en el catálogo de la exposición comisariada por Elena Santiago Páez (ed.), Ceán Bermúdez. Historiador del arte y coleccionista ilustrado, Madrid, Biblioteca Nacional de España / CEEH, 2016, págs. 89-109, que ha supuesto una puesta al día del conocimiento de la obra y la trayectoria de Ceán. 
las demás en la necesidad, la importancia y los varios destinos de sus obras»-, sus memorias exigían una publicación separada y más detenida ${ }^{4}$. De hecho, Ceán aclaró que Eugenio Llaguno ya había emprendido esta tarea, recogiendo y ordenando múltiples noticias sobre la historia de la arquitectura española. Él mismo se postuló para agregar a este trabajo manuscrito las referencias que había podido y podría descubrir en el futuro ${ }^{5}$. Y tuvo oportunidad de cumplir su palabra, puesto que tras la muerte de Llaguno en 1799 el manuscrito pasó a Ceán. En los años siguientes fue recopilando incansablemente información hasta que en 1829 apareció la que se considera la primera historia moderna de la arquitectura española, las Noticias de los arquitectos y arquitectura de España desde su restauración, por el Excmo. Señor D. Eugenio Llaguno y Amírola, ilustradas y acrecentadas con notas, adiciones y documentos por D. Juan Agustín Ceán Bermúdez. El título es revelador de la doble autoría del trabajo, si bien cabe destacar que la aportación de Ceán conforma el núcleo de mayor peso historiográfico de la obra.

En el prólogo de las Noticias se relata cómo el manuscrito de Llaguno llegó a las manos de nuestro protagonista ${ }^{6}$. También se subraya que, para completarlo, Ceán continuó sus investigaciones en distintos archivos y echó mano del material que ya había conseguido «cuando indagaba noticias para su diccionario histórico de las bellas artes» ${ }^{7}$. Las cartas que aquí publicamos confirman que, tal y como se dijo en el Diccionario y las Noticias, antes de recibir el manuscrito de Llaguno, Ceán ya había recopilado información sobre arquitectura. Es más, en la primera de las misivas se señala que fue Jovellanos quien le impulsó a ello: «Este Excmo. Señor D. Gaspar quiere que abrace en mi obra de pintores las vidas de los arquitectos».

Es conocida la destacada influencia que en los trabajos histórico-artísticos de Ceán tuvo su mentor, protector y amigo Jovellanos ${ }^{8}$. Pues bien, entre

4 Juan Agustín Ceán Bermúdez, Diccionario histórico de los más ilustres profesores de las bellas artes en España, Madrid, Viuda de Ibarra, 1800, t. I, «Prólogo», pág. Xxvi.

5 Ceán, Diccionario, t. I, «Prólogo», pág. XXIX.

6 Eugenio Llaguno y Juan Agustín Ceán Bermúdez, Noticias de los arquitectos y arquitectura de España desde su restauración, Madrid, Imprenta Real, t. I, prólogo, pág. VII y sigs. Sobre las Noticias, Daniel Crespo Delgado y Joan Domenge Mesquida, «Jovellanos: la Ilustración, las Artes y Mallorca», en Gaspar Melchor de Jovellanos, Memorias histórico-artísticas de arquitectura, Madrid, Akal, 2013, págs. 13-145; Miriam Cera Brea, «The Noticias de los arquitectos: towards a national definition of Spanish architecture», Journal of Art Historiography, 14 (2016); Daniel Crespo Delgado y Miriam Cera Brea, «Ceán y la arquitectura», en SANtiago Páez (ed.), Ceán Bermúdez, págs. 246-266. Recientemente, en 2018, Miriam Cera Brea ha defendido en la Universidad Autónoma de Madrid la tesis doctoral La historia de la arquitectura en la construcción de la identidad nacional. Las Noticias de los arquitectos de Llaguno y Ceán.

7 CEÁn, Noticias, t. I, «Prólogo», pág. XI.

8 Javier González Santos, Jovellanos (1744-1811). Aficionado y coleccionista, Gijón, Fundación Mu- 
las cartas conocidas cruzadas entre ambos encontramos una, fechada por José Miguel Caso González a principios de agosto de 1795, en la que Jovellanos instaba a Ceán a «dar lugar a los arquitectos en el nuevo diccionario» o, al menos, «a los que consta que entallaron o dirigieron obras de escultura». En la entrada de su diario correspondiente al 6 de agosto de 1795, Jovellanos anotó que era una lástima que Ceán «no abrace la arquitectura» en sus investigaciones sobre las bellas artes ${ }^{9}$. De estas referencias y de nuestras cartas podemos deducir que, cuando Ceán le comunicó sus intenciones de recoger noticias sobre artistas españoles para superar las anticuadas vidas de pintores y escultores de Antonio Palomino (1724) y el carácter parcial y los errores del Viage de España (1772-1794) de Antonio Ponz, Jovellanos le expresó el interés que tendría incorporar a los arquitectos. No parece que tuviese demasiado éxito en sus recomendaciones hasta que los dos amigos se volvieron a encontrar en Madrid a finales de 1797.

Para poder emprender la reorientación que había experimentado su obra por consejo de Jovellanos, Ceán se dirigió, como ya anotamos, al sacerdote y oficial del archivo de la catedral de Sevilla, Antonio San Martín Castillo. Pero no sólo, puesto que de igual modo hizo referencia a la ayuda que podían prestarle el penitenciario y el lectoral de la catedral: los canónigos José Gil de Araujo y Rodrigo Bernaldo de Quirós. Destaquemos que estos tres personajes fueron incluidos entre la lista de colaboradores aparecida en el Diccionario ${ }^{10}$. En una carta de finales de 1802 a uno de sus amigos y más estrechos colaboradores, José Vargas Ponce, se lamentó del reciente fallecimiento de Gil de Araujo, a quien consideraba uno de los pocos verdaderos aficionados a las bellas artes en Sevilla y con el que podía conversar sobre ellas tras su vuelta a la capital andaluza en junio de $1801^{11}$. De sus relaciones con San Martín también tenemos otras pruebas. Sin ir más lejos, cabría recordar que en su segunda estancia sevillana (1791-1797) Ceán estuvo encargado de la sistematización del Archivo General de Indias; y que a partir de 1792 se inició la reorganización del inventario

nicipal de Cultura, Educación / Universidad Popular, 1994; Crespo y Domenge, «Jovellanos: la Ilustración, las Artes y Mallorca»; Miriam Cera BreA, «Jovellanos y Ceán Bermúdez, hacia una historia de las artes en España», Anuario del Departamento de Historia y Teoría del Arte, 26 (2014), págs. 55-68; Daniel Crespo DeLGado, «Sin título», en Santiago Páez (ed.), Ceán Bermúdez, pág. 76.

9 Véase respectivamente Gaspar Melchor de Jovellanos, Obras Completas, tomo III, Correspondencia entre julio de 1794 y marzo de 1801, ed. de José Miguel Caso González, Oviedo, Centro de Estudios del Siglo XVIII / Ayuntamiento de Gijón, 1986, pág. 130 y Jovellanos, Obras completas, tomo VII, Diario, 2. ${ }^{\circ}$ (desde el 1 de septiembre de1794 hasta el 18 de agosto de 1797), ed. de María Teresa Caso Machicado y Javier González Santos, Oviedo, Instituto Feijoo de Estudios del Siglo XVIII / Ayuntamiento de Gijón, 1999, pág. 415.

10 CEÁn, Diccionario, t. I, «Prólogo», pág. XIV, nota 8.

11 Cesáreo Fernández Duro, Correspondencia epistolar de D. José Vargas y Ponce y otros en materias de Arte, Madrid, Real Academia de Bellas Artes de San Fernando, 1900, pág. 195. 
del Archivo de la Catedral de Sevilla, siendo probable un contacto entre Ceán y los archiveros responsables, Antonio de San Martín y José Ramón León ${ }^{12}$.

Por último, señalemos que en la primera de las cartas, fechada el 26 de enero de 1798, Ceán insistió en solicitar a Antonio de San Martín fechas y contratos sobre los arquitectos de la catedral de Sevilla, revelando la renovada metodología crítica que presidió sus pesquisas sobre la historia del arte español. De hecho, recientemente tuvimos la oportunidad de descubrir una relación enviada a Ceán sobre los arquitectos que intervinieron en la catedral nueva de Salamanca, elaborada en 1807 por su secretario capitular y destacable por su rigor documental ${ }^{13}$. No nos ha llegado la memoria que le remitiría San Martín, pero sabemos que la envió -no parece que el sacerdote tomase en consideración que «este trabajo no corre prisa»- por el contenido de la segunda de las cartas, del 16 de marzo de 1798. En ella, Ceán escribió que «son sumamente interesantes y curiosas las noticias de los arquitectos» que le había hecho llegar y que, «si yo pudiese hallar otras iguales en cada catedral de España, mi obra sería original, curiosa y apreciable». Afortunadamente así fue, al menos en parte, como demuestran sus enjundiosas aportaciones a las Noticias y que publicase, en 1804, la Descripción artística de la catedral de Sevilla, la primera descripción moderna de un edificio aparecida en España.

12 GaRcía LóPEZ, «Más parece hecha por una sociedad de lavoriosos individuos, que por un solo. El método de trabajo de Ceán Bermúdez», pág. 92.

13 Carta de Domingo González Valle, secretario capitular de la santa iglesia de Salamanca a Juan Agustín Ceán Bermúdez, en que refiere la historia de la construcción de aquella catedral desde 1491, hasta el de 1600, según documentos del archivo, contaduría y secretaría de aquel ilustrísimo cabildo, que ha examinado y copiado con la mayor detención, Madrid, Biblioteca Nacional de España, ms. 22.727/2; Daniel Crespo DeLGado, «Noticias desde Salamanca», en Santiago Páez (ed.), Ceán Bermúdez, pág. 265. 


\title{
DESCRIPCION ARTISTICA
}

\author{
DE LA
}

\section{CATEDRAL DE SEVILLA}

\section{POR}

D. JUAN AGUSTIN CEAN -BERMUDEZ

INDIVIDUO DE LAS REALES ACADEMIAS DE LA HISTORIA Y DE LAS NOBLES ARTES DE SAN FERNANDO DE STADRID, DE SAN CÁRLOS DE VALENCIAY DE SAN LUIS DK ZARAGOZA.

SEVILIA.

DN CASA DE LA VIUDA DE HIDATGO

I SOBRINO. 1804 


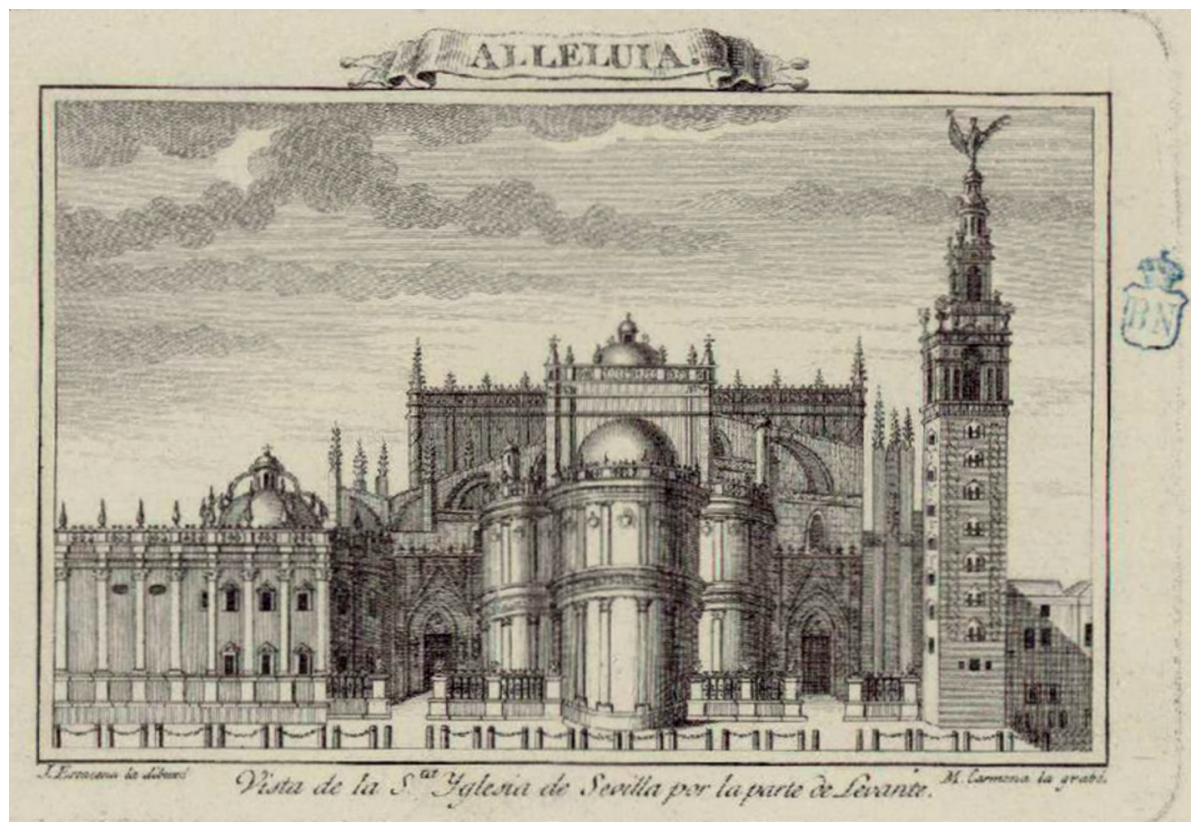

Juan Escacena (dib.), Manuel Salvador Carmona (grab.),

Vista de la Sta. Yglesia de Sevilla por la parte de Levante, 1805

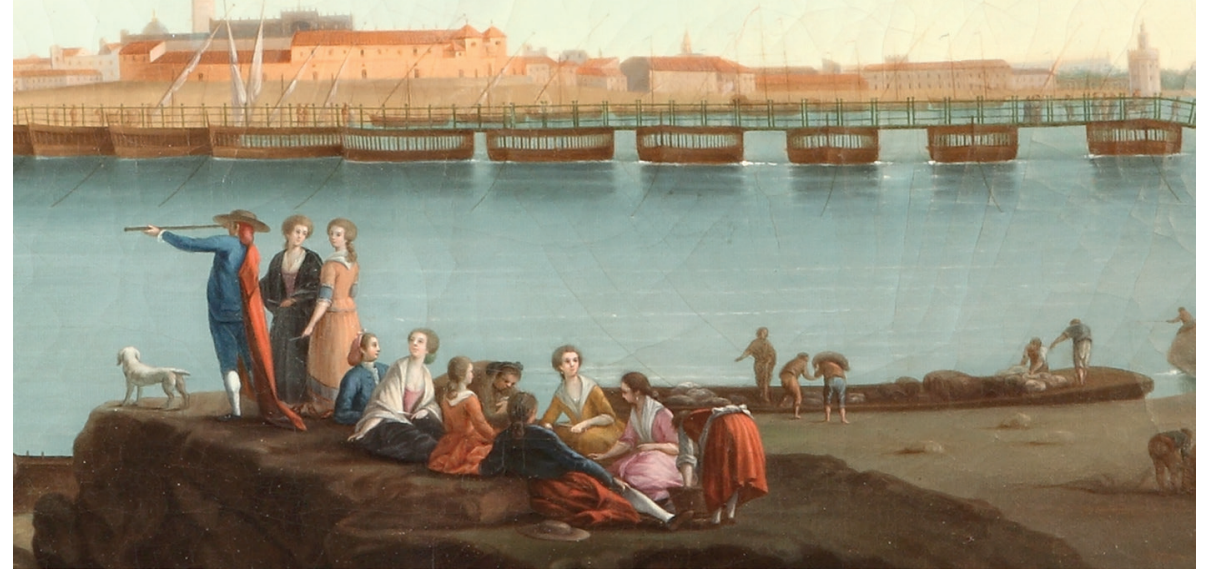

Mariano Sánchez, Puente de Sevilla (detalle), óleo sobre lienzo, Patrimonio Nacional, h. 1784 
Mi estimado amigo y señor:

Las muchas y graves ocupaciones de que estoy rodeado no me permitieron ofrecer a Vuestra Merced mi plaza de oficial de la secretaría del Despacho de Gracia y Justicia de Indias, que el rey me confirió el día 7 del corriente: lo hago ahora con buena voluntad y afecto por el que le profeso, deseando que Vuestra Merced me ocupe y mande en lo que fuere de su agrado.

Este Excmo. Señor D. Gaspar quiere que abrace en mi obra de pintores las vidas de los arquitectos, y como no fuese mi objeto cuando la bondad de Vuestra Merced me proporcionó tantas y tan buenas noticias de los artistas que trabajaron en esta Santa Iglesia, desprecié las pertenecientes a los arquitectos, y ahora me veo en la necesidad de incomodarle, suplicándole me haga el favor de recogerme todas las que buenamente pueda hallar en este bien ordenado archivo desde que se puso la primera piedra en ese gran templo; y si para esto fuese necesario recurrir a los libros o índices de los actos capitulares, podrá Vuestra Merced decirlo en mi nombre a los señores penitenciario y lectoral, que espero como amigos prestarán a Vuestra Merced todos los auxilios correspondientes.

No tengo que decir a Vuestra Merced cuánto interesan las fechas, las contratas y otras circunstancias necesarias a las vidas de los arquitectos, porque lo sabe mejor que yo; pero sí prevenir a Vuestra Merced, que este trabajo no corre prisa, y que deberá tomarle por diversión o afecto a las artes, perdonándome esta confianza fundada en el afecto que en tantas ocasiones Vuestra Merced me ha manifestado.

Saludo cordialmente al Señor León, y queda para servirle a Vuestra Merced su verdadero amigo y seguro servidor, que su mano besa

\section{Juan Agustín Ceán Bermúdez}

Si Vuestra Merced me respondiese, sea con segundo sobrescrito al Señor Don Gaspar, porque no saco cartas del correo.

Aranjuez, 16 de marzo de 1798

Mi estimado amigo y señor:

La exactitud y bondad con que Vuestra Merced evacúa mis impertinentes encargos me confunden, y no sé cómo corresponder, ni hallo expresiones cabales para manifestarle mi gratitud. Son sumamente interesantes y curiosas las 
noticias de los arquitectos, y si yo pudiese hallar otras iguales en cada catedral de España, mi obra sería original, curiosa y apreciable. Espero me continúe Vuestra Merced su favor participándome lo que halle de lo antiguo y más moderno con respecto a los artistas, así arquitectos como pintores y escultores de que yo no sepa; y le pido se sirva dar en mi nombre las más atentas gracias a los señores penitenciario y lectoral, mientras se me proporciona ocasión o tiempo, que ahora no tengo, de hacerlo por escrito.

Me ofrezco de nuevo a la obediencia de Vuestra Merced con el afecto que siempre le he profesado, su verdadero amigo y siervo, que su mano besa,

Juan Agustín Ceán Bermúdez = Antonio San Martín 